\title{
O ENSINO DE GEOGRAFIA NO CONTEXTO DA EDUCAÇÃO DO CAMPO
}

\author{
um relato sobre a escola família agrícola de Natalândia - Minas Gerais
}

\author{
Eduardo Henrique Modesto de Morais ${ }^{1}$ \\ Juliana Lopes Lelis de Morais ${ }^{2}$
}

\begin{abstract}
Resumo: O presente artigo busca compreender se o Ensino de Geografia influencia na efetivação de uma Educação do Campo no território da Escola Família Agrícola de Natalândia - MG. É possível afirmar que a Geografia pode contribuir com a Educação do Campo, pois busca refletir acerca do campo como um território de disputas e contribuir para a compreensão do campo e de seus sujeitos, além de auxiliar na recuperação e potencialização do vínculo entre a formação humana e produção material da existência dessa população, fortalecendo a identidade individual dos sujeitos e coletiva dos grupos. O presente artigo é um produto da tese de doutorado, ainda em andamento, intitulada "O Ensino de Geografia no contexto da Educação do Campo na Escola Família Agrícola de Natalândia - EFAN, Minas Gerais”.
\end{abstract}

Palavras-chave: Ensino de Geografia. Educação do Campo. Território.

\section{THE GEOGRAPHY TEACHING IN THE CONTEXT OF RURAL EDUCATION a report on the farm family school of Natalândia - Minas Gerais}

\begin{abstract}
This paper aims to understand if Geography Teaching influences the effectiveness of Rural Education in Farm Family School of Natalândia - MG territory. It is possible to affirm that Geography can contribute with Rural Education, because seek to reflect about the country as territory of disputes and contribute to the understanding of the country and their subjects, besides helping the recovery and potentialization of the link between human formation and existence's material production of this population, strengthening the individual identity of the subjects and collective's groups. This paper is a product of the doctoral thesis, still in progress, entitled "The Teaching of Geography in the Context of Rural Education at Farm Family School of Natalândia - EFAN, Minas Gerais".
\end{abstract}

Key-words: Geography teaching. Rural Education. Territory.

\section{INTRODUÇÃO}

O processo de modernização da agricultura provocou intensa diferenciação entre as regiões brasileiras e exclusão de grupos sociais. Conhecida como "Revolução Verde",

\footnotetext{
${ }^{1}$ Doutorando em Geografia pela Universidade de Brasília (UnB) na área de concentração em Gestão Territorial e Ambiental e Mestre em Educação pela Universidade Federal de Juiz de Fora - UFJF. Professor de Geografia no Instituto Federal de Educação, Ciência e Tecnologia de Minas Gerais - Campus Bambuí. Integra o grupo de pesquisa - Ensino, Aprendizagem e Formação de Professores em Geografia da Universidade de Brasília - GEAF/UnB E-mail: dumorais_17@ hotmail.com

2 Doutoranda em Geografia pela Universidade de Brasília (UnB) na área de concentração em Gestão Territorial e Ambiental e Mestre em Economia Doméstica pela Universidade Federal de Viçosa (2011). Professora de Geografia do Instituto Federal do Norte de Minas Gerais - Campus Arinos. E-mail: julianalopeslelis@gmail.com
} 


\section{REVISTA ELETRÔNICA \\ DA GRADUAÇÃO/PÓS-GRADUAÇÃO EM EDUCAÇÃO UFG/REJ}

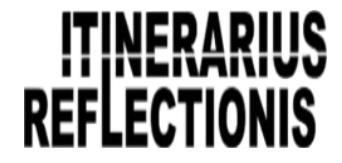

ISSN. 1807-9342

Volume 14, N. 2, 2018

a modernização agrícola trouxe para o campo uma série de novidades que envolviam um grande aparato tecnológico, a busca por plantas "perfeitas" (modificadas geneticamente, deveriam ser resistentes a pragas e alcançar altas taxas de produtividade), novos procedimentos técnicos com a inserção de fertilizantes e defensivos agrícolas, além do uso de maquinários.

No Brasil, esse processo ganhou força a partir da década de 1970, com a promessa do aumento da produção e da produtividade, aumento dos lucros e da renda no campo, além de contribuir para a produção e distribuição de alimentos. Porém, foi um fenômeno que não contribui para encurtar a distância existente entre o grande e o pequeno produtor no país, ou para distribuição de renda, ou ainda para acabar com o problema da fome, mas pelo contrário, contribui para aumentá-los. Assim, podemos afirmar que a modernização da agricultura brasileira foi extremamente conservadora, contribuindo para um processo de forte e crescente concentração fundiária (OLIVEIRA, 2010).

Nota-se que ao lado de culturas mecanizadas, permanecem as culturas rudimentares, uma vez que do avanço nos meios técnicos e produtivos não atingiram todos os produtores e propriedades. Na busca pela geração de excedentes, foram favorecidos os grandes proprietários e determinados segmentos da produção que eram de interesse da indústria e do mercado internacional.

Diante de todo esse contexto, não foi somente o modelo e a dinâmica de produção que foram alterados no campo, o perfil dos seus sujeitos também se modificou. $\mathrm{O}$ forte investimento na expansão das culturas de exportação e a consequente expulsão dos trabalhadores rurais, que em sua maioria migraram para os grandes centros urbanos, acarretou, em alguns locais, o esvaziamento da vida no campo, um enfraquecimento nas relações entre os sujeitos e, consequentemente, na cultura camponesa. Nesta perspectiva, o campo encontra-se estigmatizado na sociedade brasileira, com preconceitos, estereótipos e outras conotações multiplicando-se cotidianamente.

Mesmo ao vivenciar estas transformações, o campo ainda é marcado por especificidades locais e regionais, o que aponta a necessidade de um olhar diferenciado para a sua população. No que se refere aos aspectos educacionais, essas especificidades apontam para a necessidade da existência de uma educação voltada para a realidade da população. Se existem espaços com realidades diferentes, a educação também tem que 


\section{REVISTA ELETRÔNICA \\ DA GRADUAÇÃO/PÓS-GRADUAÇÃO EM EDUCAÇÃO UFG/REJ}

\section{ITIMERARIIUS REFLECTIONIS}

ISSN. 1807-9342

Volume 14, N. 2, 2018

ser entendida e desenvolvida de maneiras diferentes, para adequar-se às características do local em que será pensada e desenvolvida.

Porém, o que podemos perceber, é que à educação para os sujeitos do campo, não esteve presente, sendo até mesmo excluída, das políticas educacionais até meados do século XX. Desse modo, pode-se afirmar que as políticas públicas educacionais brasileiras serviram para a manutenção das relações desiguais no campo, para o acirramento das relações entre campo e cidade e, principalmente, para a perpetuação da atual estrutura fundiária.

Essa Educação do Campo, que tem caráter crítico, contra hegemônico, se estabelece em virtude de um contexto histórico de profundas alterações no campo. Centrada no saber do povo e na autonomia de suas organizações, se reproduz à margem da perspectiva educacional e da estrutura escolar hegemônica, o que não a desqualifica e/ou a torna sem importância.

A escola é vista como o objeto central, mas não é qualquer escola. A Escola do Campo é fundamental nas lutas pela Educação do Campo, como também em suas reflexões pedagógicas e auxilia na busca por uma formação omnilateral ${ }^{3}$ dos sujeitos (FRIGOTTO, 2012). Assim, escola e o processo de escolarização assumem relevante papel nas interpretações que cada sujeito constrói sobre si mesmo, sobre o outro e sobre o mundo.

Nesse sentido, as Escolas Famílias Agrícola constituem-se como um espaço de fortalecimento dos ideais da Educação do Campo e de formação integral do sujeito, para além da própria escolarização. As EFAs são escolas comunitárias, formadas a partir de uma associação de famílias de agricultores camponeses, instituições e/ou pessoas afins que, organizadas, a criaram para oferecer educação contextualizada com o campo.

As EFAs utilizam como prática pedagógica a Pedagogia da Alternância, que consiste em alternar a formação de adolescentes e jovens em um período de estudos e aprofundamentos na escola e outro de aplicação, indagação e questionamentos no meio em que vivem (SILVA, 2008).

\footnotetext{
${ }^{3}$ Formação omnilateral significa, "a concepção de formação humana que busca levar em conta todas as dimensões que constituem a especificidade do ser humano e as condições objetivas e subjetivas reais para seu pleno desenvolvimento histórico" (FRIGOTTO, 2012, p. 265). Portanto, a educação omnilateral busca a emancipação em todos os sentidos da vida humana.
} 


\section{REVISTA ELETRÔNICA \\ DA GRADUAÇÃO/PÓS-GRADUAÇÃO EM EDUCAÇÃO \\ UFG/REJ}

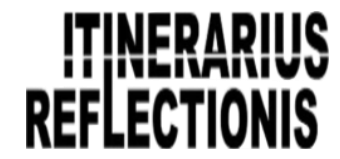

ISSN. 1807-9342

Volume 14, N. 2, 2018

Portanto, é nessa perspectiva de construção de um conhecimento crítico contrahegemônico que se insere a Geografia. Enquanto disciplina, tem como seus objetivos, o resgate, o entendimento e a valorização da identidade dos sujeitos, possibilitando as comunidades uma melhor compreensão do lugar e da realidade em que vivem. Considerando-se, conforme afirma Leite (2012), que a realidade é construída, a Geografia pode se efetivar em uma alternativa concreta de compreensão da realidade, da (re)afirmação, ou não, das identidades individual e coletiva.

Como afirma Callai (2005), a leitura do mundo é fundamental para todos nós e a possibilidade de aprender a ler, aprendendo a ler o mundo e a escrever, aprendendo a escrever o mundo, é real. Em suas palavras: “[...] é fazer a leitura do mundo da vida, construído cotidianamente e que expressa tanto as nossas utopias, como os limites que nos são postos, sejam eles do âmbito da natureza, sejam do âmbito da sociedade (culturais, políticos, econômicos)" (CALLAI, 2005, p. 228).

É nesse contexto que as categorias analíticas da Geografia - espaço, território, lugar, região e paisagem - podem contribuir com essa compreensão de mundo, principalmente se consideradas em todas as suas inter-relações e conexões, ou seja, a construção de um conhecimento, a partir da compreensão de como essa realidade é construída, percebida e vivenciada. Em linhas gerais, esse é o papel da Geografia na escola (CALLAI, 2005), e aqui se encontra a relação fundamental entre a Geografia e a Educação do Campo. Mas como o Ensino de Geografia, então, se relaciona com a Educação do Campo?

Um caminho pode ser a contextualização dos seus conceitos e temas com as formas de trabalho, de uso e luta pela terra, das tradições culturais, modos de vida, as contradições existentes, os diferentes projetos de desenvolvimento do campo, entre outros, de forma a valorizar e reconhecer o campo e seus sujeitos como seres históricos, pertencentes a espaços e tempos distintos, com conhecimentos e vivências fundamentais para o entendimento da construção e constituição do território brasileiro.

\section{O MOVIMENTO DA EDUCAÇÃO DO CAMPO}

A Educação do Campo tem como um de seus objetivos fundamentais a busca pela transformação das condições de vida no campo, a partir da construção de uma alternativa contra-hegemônica de educação e desenvolvimento. Sendo assim, trata-se de um 


\section{REVISTA ELETRÔNICA \\ DA GRADUAÇÃO/PÓS-GRADUAÇÃO EM EDUCAÇÃO \\ UFG/REJ}

\section{TrWERPUUS \\ REFLECTONIS}

ISSN. 1807-9342

Volume 14, N. 2, 2018

instrumento de luta contra opressões e exclusões, e de formação holística e integral do ser humano (RIBEIRO, 2008). É importante ressaltar, assim conforme observa Caldart (2008, p.71): "Foi o campo, sua dinâmica histórica, que produziu a Educação do Campo".

A Educação do Campo identifica a construção de um projeto educativo, que reafirma a importância da ação educativa como forma de humanização e inserção crítica dos sujeitos na sociedade (CALDART, 2004). Isso se faz a partir da perspectiva do campo e do camponês, e entende que a luta é educativa e essa mesma luta que irá redefinir o campo, o tipo de desenvolvimento. Assim, a Educação do Campo, ainda segundo Caldart (2004), só pode ocorrer junto com a transformação das circunstâncias sociais desumanizadoras e a partir da ascensão dos povos do campo como sujeitos destas transformações.

Pensado pelo conjunto de trabalhadores e trabalhadoras do campo, a Educação do Campo busca o resgate do conceito de camponês em toda a sua diversidade. Assim, não é possível se pensar em uma política educacional do campo desvinculada das questões do trabalho, da cultura, do embate de projetos de campo, de modelos agrícolas e suas implicações para o país, de sociedade (CALDART, 2015). A valorização desses vínculos estabelece que a luta da Educação do Campo seja por uma nova perspectiva formativa e, consequentemente, por uma nova escola.

A Educação do Campo só pode ocorrer junto com a transformação das circunstâncias sociais desumanizadoras e a partir do empoderamento dos povos do campo como sujeitos destas transformações. Entende-se, então, que ela é uma obra dos sujeitos do campo e para os sujeitos do campo.

Uma educação que pertence a eles e que, ao mesmo tempo, foi construída por eles, que objetiva questões fundamentais, vinculadas ao modo de vida e ao trabalho no campo, considerando que essa população possui o direito que a sua educação seja no campo e do campo. No campo, porque o povo tem o direito desta ser desenvolvida no meio em que vivem e, do campo, porque ela deve ser (re)pensada em conjunto com essa população, sempre vinculada a sua realidade (CALDART, 2004).

Desenvolve-se assim, na diversidade e envolve uma gama de sujeitos que convivem e trabalham no campo e vivenciam constantemente processos de territorialização, desterritorialização e reterriorialização (HAESBAERT, 2016), que são movimentos dinâmicos no/do território, que não significam a simples mudança de 


\section{REVISTA ELETRÔNICA \\ DA GRADUAÇÃO/PÓS-GRADUAÇÃO EM EDUCAÇÃO \\ UFG/REJ}

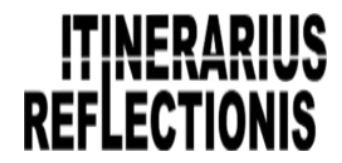

ISSN. 1807-9342

Volume 14, N. 2, 2018

lugares, mas também, de formas de pensar e organizar o espaço, vivenciar e expressar a cultura. São movimentos que se espacializam, por exemplo, na luta pela terra e pela qualidade de vida, trabalho e educação no e a partir do campo. Nesse sentido, ela deve também pensar a lógica da vida no campo em suas múltiplas e diversas dimensões (CALDART, 2008).

O protagonismo dos movimentos e organizações sociais na busca pela conquista dos direitos das populações do campo nos mostram alguns avanços, porém, sem se esquecer das grandes dificuldades e problemas extremamente graves que os sujeitos do campo ainda vivenciam. São eles: a conquista de importantes marcos legais; legislações nacionais; os programas educacionais destinados a estes sujeitos; a abertura de espaços nas universidades públicas (linhas de pesquisa de mestrado e doutorado em Educação do Campo; Licenciatura em Educação do Campo); a ampliação da capacidade de articulação entre os diferentes sujeitos coletivos e as organizações; a ampliação dos fóruns estaduais, entre outros (FONEC, 2012).

Os desafios político-organizativos que se colocam para a continuidade dessa caminhada da Educação do Campo são: reafirmar e fortalecer a Educação do Campo através do aperfeiçoamento da sua forma organizativa, de maneira coletiva; defender e garantir o protagonismo das organizações de trabalhadores do campo na condução da Educação do Campo; dar continuidade e fortalecer a construção de uma base teórica comum, buscando uma unidade política entre os diferentes sujeitos; organizar ações coletivas de combate ideológico ao agronegócio; associar às ações de denúncia e resistência às reformas empresariais da educação em curso no Brasil; radicalizar as lutas coletivas pelo acesso a educação pública de qualidade; e fortalecer a cooperação entre práticas que explicitem o confronto da matriz formativa na especificidade do campo (CALDART, 2015).

As Escolas do Campo nesse contexto de desafios se tornam fundamentais para o fortalecimento e formação crítica dos sujeitos do campo. Nessa perspectiva, as escolas do campo ganham destaque e importância de serem pensadas como parte de um projeto maior de educação da classe trabalhadora, a partir das possibilidades de atuação das instituições educativas, que estão além das funções tradicionalmente reservadas à escola, como a da socialização, a construção e transmissão de conhecimentos. 


\section{REVISTA ELETRÔNICA \\ DA GRADUAÇÃO/PÓS-GRADUAÇÃO EM EDUCAÇÃO \\ UFG/REJ}

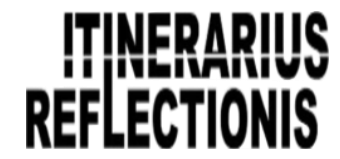

ISSN. 1807-9342

Volume 14, N. 2, 2018

Diante do desafio cotidiano da Educação do Campo em construir uma lógica pedagógica que se centre no sujeito coletivo e não apenas na escola, fica evidente a importância das relações simbólicas construídas no território ao qual esse sujeito pertence, o contexto social no qual ele vive e o movimento no qual ele apoia sua afirmação enquanto sujeito.

\section{ESCOLAS DO CAMPO: a territorialização da educação do campo na busca pela formação dos sujeitos}

As Escolas do Campo inserem-se na perspectiva Gramsciana de Escola Unitária, pois através de estratégias pedagógicas e epistemológicas buscam a formação omnilateral e a formação de intelectuais da classe trabalhadora (MOLINA; MOURÃO, 2012). Sendo assim, ela se coloca em um desafio de conceber e desenvolver um processo mais amplo de transformação social, ou seja, uma formação contra-hegemônica.

As Escolas do Campo são de extrema importância na criação de condições que contribuam para a promoção do desenvolvimento das comunidades camponesas, desde que se promova, no seu interior, importantes transformações, tanto na (re)construção de seus projetos educativos, como no currículo e na organização do trabalho pedagógico (MOLINA; MOURÃO, 2012).

Neste contexto é necessário se buscar a transformação da forma escolar, vinculando-a organicamente aos interesses sociais e culturais dos trabalhadores, transformando, fundamentalmente, o formato das relações sociais que acontecem no seu interior. A forma escolar atual é fruto de uma configuração histórica. A nova forma escolar deve se abrir para a vida e incluir outras fontes formativas tão importantes quanto à escolar.

O ponto de partida de uma forma escolar contra-hegemônica é exatamente a escola capitalista. Esta se mostra como um instrumento de dominação e uma ferramenta para reprodução do sistema, cultivando valores de obediência e submissão, explícitos nos conteúdos curriculares e na forma hierárquica e bancária de organização escolar. A forma de subversão da forma escolar clássica é a constituição de uma organização coletiva que altere a lógica estabelecida. A partir dessa constatação, se vê a necessidade de 


\section{REVISTA ELETRÔNICA \\ DA GRADUAÇÃO/PÓS-GRADUAÇÃO EM EDUCAÇÃO \\ UFG/REJ}

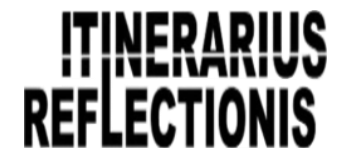

ISSN. 1807-9342

Volume 14, N. 2, 2018

rompimento com essa forma escolar clássica, exercitando relações pedagógicas que permitam uma aprendizagem menos autoritária (FARIAS, 2015).

Sendo assim, as escolas podem se configurar como um espaço de resistência, a partir da incorporação dos ideais da Educação do Campo e da Educação Popular, como um espaço de fortalecimento dos e de formação integral do sujeito, para além da própria escolarização.

Para Molina e Mourão (2012), algumas importantes vitórias vêm sendo conquistadas pelos movimentos sociais na luta pela construção da concepção da Escola do Campo. Primeiro, foi reconhecer e utilizar a expressão Escola do Campo, demarcando uma diferenciação em relação a escola rural. Segundo a construção do Projeto Político Pedagógico das Escolas do Campo como instrumento de legitimação das práticas e experiências vivenciadas nesses espaços. E terceiro, o estabelecimento na Política Nacional de Educação do Campo (Decreto $n^{\circ} 7.352 / 2010$ ), do que se compreende por Escola do Campo, demarcando que a sua identidade se dá pela posição geográfica, mas também pelos sujeitos que ela acolhe.

No que se refere às questões que ainda devam ser pensadas pelas Escolas do Campo, para que elas atuem de acordo com os princípios da Educação do Campo, destacam-se: o cultivo de formas e estratégias que garantam a participação da comunidade, enxergando nela uma aliada para o enfrentamento dos problemas e a construção das soluções; superar a prioridade dada aos indivíduos isoladamente, cultivando as experiências e vivências coletivas, até mesmo na gestão da escola; superação da separação entre trabalho manual e intelectual, entre teoria e prática, inserindo o trabalho socialmente útil nos processos formativos vivenciados na escola; a ressignificação do conhecimento científico através da materialização da vida real dos educandos; e a formação de intelectuais orgânicos da classe trabalhadora e, especificamente, do campo (MOLINA; MOURÃO, 2012).

Nessa diversidade de projetos e práticas de Educação do Campo se inserem as Escolas Famílias Agrícola (EFAS). Na busca pela formação integral dos alunos e a valorização do campo, as EFAs veem na articulação entre a escola e a comunidade, a possibilidade de uma aprendizagem contínua, atrelada aos conhecimentos, vivências e especificidades de cada sujeito e/ou comunidade. 


\section{REVISTA ELETRÔNICA \\ DA GRADUAÇÃO/PÓS-GRADUAÇÃO EM EDUCAÇÃO \\ UFG/REJ}

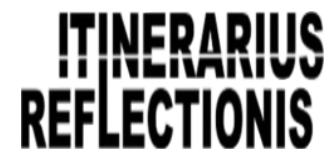

ISSN. 1807-9342

Volume 14, N. 2, 2018

A proposta das EFAs é fundamentada nos princípios filosóficos e metodológicos dos Centros Familiares de Formação por Alternância - CEFFAs, que adotam quatro pilares básicos: a) A Associação Gestora, de responsabilidade de famílias, pessoas e entidades afins; b) A Pedagogia da Alternância como estratégia de organização dos tempos escolares e de formação apropriada à realidade, mediante integração da prática com a teoria; c) A formação Integral e personalizada e; d) O desenvolvimento local sustentável e solidário.

Nesse sentido, as EFAs constituem-se como um espaço de fortalecimento dos ideais da Educação do Campo e de formação integral do sujeito, para além da própria escolarização. Sendo assim, podemos relacionar as Escolas do Campo, em especial as EFAs, enquanto territórios da Educação do Campo a partir da valorização e do fortalecimento dos conhecimentos e da identidade camponesa.

\section{TERRITÓRIO E TERRITORIALIDADES CAMPONESAS}

Os conceitos de território e territorialidade, por tratarem de questões referentes a espacialidade humana, acabam por aparecer também em outras áreas, a partir de diferentes perspectivas (HAESBAERT, 2016). Na Geografia, tende-se a enfatizar, em maior número, os aspectos materiais que o conceito carrega em todas as suas dimensões (cultural, política, econômica, entre outros).

Falando especificamente sobre o conceito território, este se apresenta enquanto elemento chave na compreensão dos processos econômicos, políticos, sociais e culturais vivenciados pela sociedade, devido a possibilidade de sua utilização para além de um sentido físico, rígido, demarcado, mas também por poder considerar a sua dimensão simbólica, fruto das relações que se apresentam e/ou são estabelecidas durante esses processos. Esse entendimento, portanto, implica na aceitação da indissociabilidade entre espaço e sociedade.

De acordo com Haesbaert (2016), é importante discutir a conceituação de território segundo os binômios:

a) O binômio materialismo-idealismo, desdobrando em função de duas outras perspectivas: i. a visão que denominamos "parcial" de território, ao enfatizar uma dimensão (seja a "natural", a econômica, a política ou a cultural); ii. A perspectiva 


\title{
REVISTA ELETRÔNICA \\ DA GRADUAÇÃO/PÓS-GRADUAÇÃO EM EDUCAÇÃO UFG/REJ
}

\begin{abstract}
"integradora" de território, na resposta a problemática que, "condensadas" através do espaço, envolvem conjuntamente todas aquelas esferas.

b) O binômio espaço-tempo, em dois sentidos: i. seu caráter mais absoluto ou relacional: seja no sentido de incorporar ou não a dinâmica temporal (relativizadora), seja na distinção entre entidade físico-material (como "coisa" ou objeto) e socialhistórica (como relação); ii. Sua historicidade e geograficidade, isto é, se se trata de um componente ou condição geral de qualquer sociedade e espaço geográfico ou se está historicamente circunscrito a determinado(s) período(s), grupo(s) social(is) e/ou espaço(s) geográfico(s) (HAESBAERT, 2016, p. 41).
\end{abstract}

A partir dessa reflexão, verifica-se que o conceito de território somente será utilizado para a análise socioespacial quando considerar o seu uso, a partir do momento em que ele é entendido juntamente com os sujeitos que o utilizam (SANTOS, 2009), principalmente na atual dinâmica capitalista do "meio técnico-científico-internacional" (HAESBAERT, 2016).

Nessa perspectiva, o território deve ser compreendido a partir do seu contexto histórico de formação, com referência às relações sociais estabelecidas. É imprescindível, portanto, contextualizar historicamente o território considerado. Sendo assim, o conceito de território só pode ser concebido através uma "perspectiva integradora" (HAESBAERT, 2016). Integradora entre as diferentes dimensões sociais, enquanto um espaço que não pode ser entendido isoladamente por seus aspectos naturais, econômicos, sociais, políticos ou culturais, nem também apenas pelos seus aspectos materiais, pela demarcação de fronteiras fixas, rígidas.

Conforme Haesbaert (2016) fica evidente, neste ponto, a partir da compreensão integradora do território, a necessidade da concepção do espaço como um híbrido, “[...] híbrido entre sociedade e natureza, entre política, economia e cultura, e entre materialidade e idealidade, numa complexa interação espaço-tempo [...]" (HAESBAERT, 2016, p. 79).

Sua constituição, portanto, tem presente a natureza e sociedade; economia, política e cultura; identidade e representações; dominação e subordinação; (des)continuidades; terra, espaço e poder; diversidade, desigualdade, diferença, traços comuns, entre tantos outros (SAQUET, 2007). Cada elemento, bem como a as diversas possibilidades de combinação dos mesmos, estabelecem relações específicas, particulares a cada espaço-tempo, o que possibilita constituir, permear e condicionar os fenômenos e 


\section{REVISTA ELETRÔNICA \\ DA GRADUAÇÃO/PÓS-GRADUAÇÃO EM EDUCAÇÃO \\ UFG/REJ}

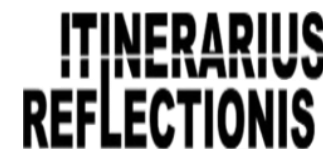

ISSN. 1807-9342

Volume 14, N. 2, 2018

processos territoriais. Nessa perspectiva, os territórios podem se configurar como a identidade material e imaterial de um grupo.

Os territórios, nesse sentido, podem ser condição e meio para a reprodução social. Permite que, através da identidade e das relações próprias de cada grupo, mantenham a sua reprodução social. Nessa perspectiva, o território é uma área onde seus ocupantes se apoderam de um espaço, seja este concreto ou simbólico. Em outras palavras, uma dada porção do espaço geográfico onde se estabelecem todas as relações sociais, econômicas, culturais, políticas de um grupo, necessárias e/ou inerentes a sua reprodução social (SANTOS e SILVEIRA, 2004).

No entanto, o território não é composto e nem se apresenta somente enquanto a síntese equilibrada dos atores e das relações estabelecidas em seu interior. Ele agrega complexas relações de poder de diferentes naturezas, poder dos atores sociais, poder político da conjuntura nacional e internacional, de corporações econômicas, por exemplo. Esse poder que emerge dos interesses e conflitos no território é uma categoria central para a compreensão da dinâmica espacial.

Sendo assim, para o entendimento do território se faz necessária a superação de concepções simplistas que compreendem o território sem os sujeitos ou esses sujeitos sem territórios. É preciso apreender a complexidade e unidade do mundo da vida, de maneira (i)material, as relações com/nos lugares (SAQUET, 2007). É importante entender que a sociedade está em permanente diálogo com o "território usado" (SANTOS, 2009), sendo que esse diálogo está permeado de aspectos naturais e artificiais, de vivências sociais, em constante movimento.

Nesse sentido, quando buscamos compreender um indivíduo ou um grupo social mais coeso, como é o caso dos assentamentos presentes no município de Natalândia $\mathrm{MG}^{4}$, pois acredita-se, conforme Haesbaert (2016), que estes constroem seus (multi)territórios integrando, de alguma maneira, em um mesmo conjunto, as experiências econômicas, políticas e culturais estabelecidas em suas relações com o espaço. As condições para essa realização incluem a maior diversidade territorial, uma

\footnotetext{
${ }^{4}$ Cito aqui em especial o município de Natalândia - MG pois é no território desses assentamentos que fica localizada a Escola Família Agrícola de Natalândia - EFAN, cujo sujeitos são o cerne desse trabalho.
} 


\section{REVISTA ELETRÔNICA \\ DA GRADUAÇÃO/PÓS-GRADUAÇÃO EM EDUCAÇÃO UFG/REJ}

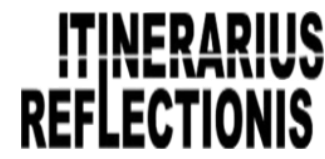

ISSN. 1807-9342

Volume 14, N. 2, 2018

grande disponibilidade de redes/conexões e a abertura cultural "para efetivamente usufruir e/ou construir essa multiterritorialidade” (HAESBAERT, 2016, p.343).

Podemos afirmar assim que, em Natalândia - MG, essa multiterritorialidade se faz presente na luta pela terra: em meados da década de 1980 até a desapropriação das fazendas; em 1995, com a consolidação/demarcação de três assentamentos e posterior entrega as famílias; na busca pelo regate e valorização dos saberes e experiências de um povo, através do fortalecimento da sua identidade e da consolidação de um território cultural; na demarcação do terreno para construção da Escola Família Agrícola de Natalândia - EFAN, bem como na influência de suas ações em toda a região, o que chamo nesse trabalho da construção de um território educativo que fortalece a permanência do jovem no campo; e, por fim, o território construído pela rede de Escolas Famílias Agrícolas estaduais e nacionais, fortalecendo as EFAs como uma proposta educativa contra-hegemônica para os povos do campo.

A (re)produção, bem como a construção e o estabelecimento desses vínculos com o território, onde se fazem presentes, em grande medida, o esforço coletivo estabelecido pelo grupo para ocupar, se identificar, controlar e se (re)produzir no seu ambiente é denominado de territorialidade (LELIS, 2011). A territorialidade contém as características de um território, sua materialidade e imaterialidade. Territorialidade seria uma forma de vínculo do homem ao meio. Envolve nessa perspectiva, uma ordem de subjetividade coletiva, que possibilita aos grupos sociais articulações territoriais de resistência.

Para Haesbaert (2016),

[...] não se trata simplesmente de priorizar o expressivo sobre o funcional, mas de reconhecer sua permanente imbricação. Se o território hoje, mais do que nunca, é também movimento de feições meramente funcionais: ele é também um movimento dotado de significado, de expressividade, isto é, que tem um significado determinado para quem o constrói e/ou para quem dele usufrui (HAESBAERT, 2016, p. 281).

A territorialidade, portanto, resultado e determinante no processo de (re)produção dos territórios, é múltipla. Sendo assim, os territórios também são múltiplos e revelam a complexidade social. O espaço, enquanto meio e condição de reprodução de relações sociais, ganha expressão na existência de territórios e na configuração de territorialidades. 


\section{REVISTA ELETRÔNICA \\ DA GRADUAÇÃO/PÓS-GRADUAÇÃO EM EDUCAÇÃO UFG/REJ}

A compreensão dos comportamentos humanos é feita, também, através da compreensão das formas de relacionamento do homem com o espaço (LELIS, 2011).

Portanto, entendemos o território como a identidade espacial de um grupo, através da apropriação material e simbólica do espaço, de maneira contínua ou não. Assim, acredito que os territórios e as territorialidades camponesas permitem os estabelecimentos de laços que são condição e meio para o fortalecimento da identidade camponesa e da sua (re)produção social.

Conforme afirma Fernandes (2012), podemos dizer então que o território camponês é uma unidade espacial, caracterizada pelo seu uso. Essa unidade espacial se transforma em território camponês quando compreendemos que a relação social que o constrói é o trabalho familiar, associativo, comunitário, cooperativo, enquanto condição fundamental para a reprodução familiar e comunitária. Segundo Fernandes (2012),

A prática dessa relação social assegura a existência do território camponês, que, por sua vez, promove a reprodução dessa relação social. Essas relações sociais e seus territórios são construídos e produzidos, mediante a resistência, por uma infinidade de culturas camponesas em todo o mundo, num processo de enfrentamento permanente com as relações capitalistas (FERNANDES, 2012, p. 746).

$\mathrm{O}$ entendimento dos territórios e territorialidades camponeses perpassa pela compreensão das diferentes relações estabelecidas entre as pessoas e/nos lugares. Contribuindo, assim, para a reprodução/materialização desse território e, consequentemente, no fortalecimento da identidade e das memórias coletivas dos sujeitos que no campo criam e reproduzem suas existências.

Porém, como identificar o fortalecimento no contexto daqueles que são/estão do/no campo? Acredita-se que o Ensino de Geografia pode ser um caminho a partir do momento em que este se desenvolve (conceitos, conteúdos e temas) por meio da valorização dos conhecimentos e vivências construídas durante o processo de resistência e de construção da identidade campesina, na luta pela terra, na (re)produção das suas práticas espaciais e, até mesmo, na construção de novas referências identitárias e de (re)territorialização. 


\section{REVISTA ELETRÔNICA \\ DA GRADUAÇÃO/PÓS-GRADUAÇÃO EM EDUCAÇÃO \\ UFG/REJ}

\section{O ENSINO DE GEOGRAFIA NO CONTEXTO DA EDUCAÇÃO DO CAMPO}

Após a metade do século XX, o campo passou por uma série de modificações, entre as quais se destaca o processo de modernização agrícola. A realidade dos povos do campo no Brasil atestou que apenas uma pequena parcela dessa população foi beneficiada, permanecendo a grande maioria à margem desse processo.

O ensino, nesse contexto, seguia os ideais nacionalistas e funcionava, em grande parte, como um mecanismo de controle do Estado. Aos sujeitos do campo eram impostos os modelos pedagógicos uniformes, que ora os marginalizava, ora vinculava-os ao mundo urbano, desconsiderando sua diversidade sociocultural e sua prática social (ALVES e MAGALHÃES, 2008). As políticas públicas educacionais, que surgiram na ocasião, serviram de base para grande parte dos textos legais, que legislam nosso sistema educativo e a formação de professores.

Caracterizado por uma abordagem considerada tradicional, de fundamentação positivista, centrada em atividades de memorização e descrição, o ensino de Geografia desse período histórico estudava os conteúdos de maneira fragmentada, não permitindo ao aluno a oportunidade de entendê-los em sua totalidade, relacionando-os entre si.

Diante do exposto, podemos afirmar que as propostas de Educação do Campo e de um Ensino de Geografia foram influenciadas a partir das contradições sociais decorrentes do modelo de desenvolvimento adotado pelo país, desde a mudança no padrão de acumulação iniciada por Vargas, de um modelo agrário para um urbano industrial (LEITE, 2012), o qual influenciou sobremaneira o processo de modernização agrícola e as políticas educativas e educacionais da ocasião.

Notadamente, foi a partir da década de 1970, quando as questões de cunho social se impuseram à análise geográfica e culminaram por fornecer possibilidades de investigação pautada em outras fundamentações filosóficas, que não o positivismo, surgiram caminhos alternativos à pesquisa, sobre as relações do homem/sociedade no/do campo. Em consequência, a contribuição dessa área se manifesta pela compreensão dos processos sociais, relacionados à dinâmica social no espaço e no tempo.

Atualmente, observa-se que, de maneira mais geral, a Geografia contemporânea em muito difere daquela abordagem tradicional, na medida em que busca valorizar o cotidiano, busca a (re)construção didática do conteúdo e o envolvimento dos diferentes 


\section{REVISTA ELETRÔNICA \\ DA GRADUAÇÃO/PÓS-GRADUAÇÃO EM EDUCAÇÃO \\ UFG/REJ}

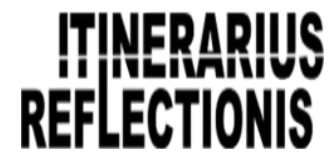

ISSN. 1807-9342

Volume 14, N. 2, 2018

grupos sociais presentes no contexto escolar e na comunidade onde se situa a escola (LEITE, 2012). Tais características evidenciam o potencial da Geografia no enfrentamento das questões postas pela Educação do Campo.

Pela afirmação de Vesentini (1992), relativa ao Ensino de Geografia, de um modo geral, pode-se inferir o potencial para as particularidades presentes na perspectiva escolar desse conhecimento, no contexto da Educação do Campo:

Consiste em uma Geografia escolar ligada à realidade do educando, onde este sinta que, através desse estudo, passou a refletir e compreender melhor o mundo em que vive - desde a escala planetária até a nacional e a local, podendo então se posicionar conscientemente a essa realidade histórica com suas contradições, conflitos e mudanças (VESENTINI, 1992, p. 89).

Buscar essa compreensão da realidade não é um objetivo exclusivo da Geografia. Entretanto, ao fazê-lo pela dimensão espacial, imputa uma nova perspectiva de análise, passível de contribuir, efetivamente, com a compreensão da realidade. Nesse sentido, no âmbito escolar, esse intento pode ser alcançado por meio de suas categorias analíticas espaço, território, lugar, região e paisagem, notadamente em todas suas inter-relações e conexões.

A abordagem geográfica da realidade, ao ser efetuada com base nos conceitos e categorias, possibilita olhar a realidade socioespacial, considerando as particularidades dos sujeitos envolvidos. Nesse sentido, deve ser assinalada como um processo de construção de conhecimento geográfico, ou seja, a construção de um conhecimento a partir da compreensão de como essa realidade é construída, percebida e vivenciada. Desse modo, os conteúdos precisam estar sistematizados de forma a reconhecê-los e valorizálos enquanto pertencentes a espaços e tempos distintos, de extrema importância para uma aprendizagem significativa e, assim, para a formação humana (OLIVEIRA, 2011).

Assim, é possível afirmar que a Geografia poderá contribuir com a Educação do Campo, pois ela auxiliará "[...] para que se encontrem, se organizem e assumam a condição de sujeitos e da direção dos seus destinos" (CALDART, 2004, p. 149). Apesar de possuírem contextos e tempos de reflexão e criação distintos, a Educação do Campo, as Escolas do Campo e o Ensino de Geografia buscam refletir acerca do campo como um território de disputas e contribuir para o seu fortalecimento e de seus sujeitos. 


\section{REVISTA ELETRÔNICA \\ DA GRADUAÇÃO/PÓS-GRADUAÇÃO EM EDUCAÇÃO \\ UFG/REJ}

\section{OS CONTEÚDOS OFICIAIS: os conteúdos básicos comuns de Geografia para o}

\section{Ensino Médio}

Os Conteúdos Básicos Comuns - CBCs, foram implementados no estado de Minas Gerais pela Resolução SEE nº 666, de 7 de abril de 2005. Esta traz em seu caput que a resolução: "Estabelece os Conteúdos Básicos Comuns - CBCs a serem obrigatoriamente ensinados pelas unidades de ensino estaduais que oferecem as séries finais do ensino fundamental e ensino médio" (RESOLUÇÃO SEE No 666, 2005). Tem como documentos referência para a sua construção a Base Nacional Curricular Comum - $\mathrm{BNCC}^{5}$, e os Parâmetros Curriculares Nacionais - PCNs ${ }^{6}$.

Os CBCs trazem os conteúdos básicos, bem como as competências e habilidades que são consideradas necessárias para a formação dos alunos. Dessa forma, apresentam, primeiramente, o eixo temático, tema e subtemas, e posteriormente, os tópicos/habilidades principais a serem trabalhados no interior daquela temática e, também, as habilidades detalhadas que se espera que os alunos alcancem ao final do desenvolvimento do conteúdo.

O CBC de Geografia para o Ensino Médio em suas páginas iniciais deixa claro que os critérios utilizados para a seleção de conteúdos perpassam por critérios científicos (pluralidade de abordagens e entendimentos do espaço geográfico), tecnológicos (modernização econômica aliada as questões ecológicas) e pedagógicos (conceitos, procedimentos e atitudes). Assim, pode-se perceber que ser escola urbana ou do campo, estar localizada em grandes, médias ou pequenas cidades, as diferenças culturais regionais, entre outras características vinculadas as escolas, acabam por não serem consideradas nessa seleção. Assim, mesmo sendo um currículo único, básico a ser adotado em todas as escolas públicas do estado de Minas Gerais, o CBC não aborda/cita

\footnotetext{
${ }^{5}$ De acordo com o documento, a BNCC "é um documento de caráter normativo que define o conjunto de aprendizagens essenciais que todos os alunos devem desenvolver ao longo das etapas e modalidades da Educação Básica [...] de modo a que tenham assegurados seus direitos de aprendizagem e desenvolvimento" (BNCC - MEC, 2018).

${ }^{6}$ Os PCNs são diretrizes que servem como referência, para estados e municípios, na construção dos currículos. Além dos conteúdos, trazem também procedimentos e atitudes que podem ser seguidos por professores na sala de aula. Não é um documento obrigatório, mas foram amplamente adotados e é a base para a construção de muitos materiais didáticos adotados atualmente.
} 


\section{REVISTA ELETRÔNICA \\ DA GRADUAÇÃO/PÓS-GRADUAÇÃO EM EDUCAÇÃO \\ UFG/REJ}

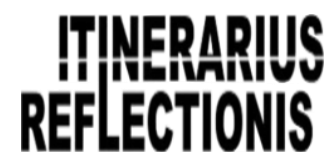

ISSN. 1807-9342

Volume 14, N. 2, 2018

as especificidades locais e, tampouco, as diversidades regionais presentes em um estado com 853 municípios.

Portanto, o Campo, as Escolas do Campo e os seus sujeitos, acabam por ter em mãos uma série de conteúdos básicos que são idênticos aos selecionados para as escolas urbanas, aspecto que não é novidade nas políticas educacionais brasileiras. É importante lembrar que o Decreto 7.352, de 4 de novembro de 2010, que institui a Política Nacional de Educação do Campo, bem como o Decreto estadual n n $^{\circ} 6.218$, de 15 de abril de 2013, que institui as Diretrizes Estaduais para a Educação do Campo de Minas Gerais, possibilitam a adaptação do currículo e carga-horária, por exemplo, a realidade das localidades que estas escolas encontram-se inseridas, aos ciclos agrícolas, aos períodos de seca/chuva, entre outras, porém, na grande maioria das vezes, por falta de condições financeiras, estrutura física, mobilidade/transporte, entre outros, essa adaptação acaba por não acontecer.

Quando tratamos especificamente da realidade das EFAs mineiras, apesar de estarem atreladas as diretrizes e políticas educacionais estabelecidas pelo Estado de Minas Gerais, possuem uma organização e autonomia diferenciadas e tem, na adoção da Pedagogia da Alternância, uma nova possibilidade de ação e de adaptação dos tempos e espaços escolares.

Apesar de não trazer especificamente os conteúdos adequados/adaptados a realidade das Escolas do Campo, o CBC em seus eixos II e VI, aborda as habilidades que considera necessárias para o conhecimento dos alunos a partir de temas diretamente ligados ao Campo. Pode-se considerar ainda que os temas presentes no Eixo Complementar VI, no que se refere a relação com a Educação do Campo, estão ainda mais conectados a realidade dos sujeitos camponeses, principalmente quando abordam a questão do Trabalho, da Estrutura Fundiária, as Territorialidades, a Reforma Agrária e os Movimentos Sociais Camponeses.

De maneira geral, todos os outros eixos e seus respectivos conteúdos apresentam ligações com o Campo e com a realidade dos seus sujeitos. Essa ligação, é claro, vai depender da maneira como esse conteúdo será desenvolvido, pois o tópico é apresentado pelo CBC, porém os conteúdos a serem desenvolvidos, bem como a relação com outros conteúdos não são explícitos no documento. 


\section{O CAMINHO TRILHADO PELA PESQUISA}

Esta pesquisa de base qualitativa foi realizada por meio da análise documental do Projeto Político Pedagógico da EFAN, do Currículo Básico Comum - CBC, produzido pela SEE/MG, bem como do diário de campo, que registrou as observações de aulas, atividades extraclasse desenvolvidas, sentimentos e impressões, entre outras; entrevista semiestruturada com duas lideranças da comunidade para o entendimento do percurso histórico de criação do território da Educação do Campo nos assentamentos, além de entrevistas com o professor da disciplina de Geografia, o coordenador pedagógico, supervisora do Ensino Médio com o objetivo de entender a dinâmica da EFAN, bem como o papel da Geografia na formação dos alunos e na consolidação do território camponês e; grupo focal, aqui denominado de roda de conversa, com os alunos do $3^{\circ}$ ano do Ensino Médio. Além disso, ocorreu a participação em outros momentos de formação a partir do convite da instituição. Essas ações foram realizadas durante dois anos e a partir de agendamento prévio, ou por solicitação da própria escola. Esses momentos tiveram a duração entre um e cinco dias de inserção.

\section{A ESCOLA FAMÍLIA AGRÍCOLA DE NATALÂNDIA - EFAN: no contexto do noroeste mineiro}

O Noroeste de Minas Gerais reúne uma complexa gama de características geográficas, históricas, demográficas, econômicas e culturais. Podemos assim observar que essas diferentes características se traduzem na existência de vários territórios, sejam eles físicos, materiais, como também subjetivos, imateriais. Muitos deles apresentam características bastante específicas, fator este que os diferencia e lhes atribui características e identidade próprias.

De maneira geral, o noroeste mineiro é conhecido: por suas tradições culturais, marcada pela realização de diversas manifestações e festividades ligadas a aspectos religiosos, personalidades e fatos históricos; pelas riquezas naturais atreladas ao turismo ecológico; por uma economia marcada, por um lado, pela grande importância do setor agrícola no cenário nacional, bem como pela ampliação do setor secundário e terciário e, por outro, pela presença da agricultura familiar, pela concentração de terra e pelos seus conflitos, por um grande número de assentamentos e projetos de assentamentos de 


\section{REVISTA ELETRÔNICA \\ DA GRADUAÇÃO/PÓS-GRADUAÇÃO EM EDUCAÇÃO \\ UFG/REJ}

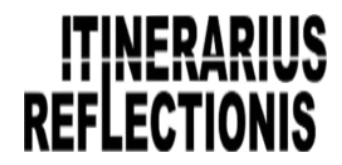

ISSN. 1807-9342

Volume 14, N. 2, 2018

reforma agrária, atrelados esses fatores a um Índice de Desenvolvimento Humano Municipal (IDHM) de 0,692, classificado como médio, em uma escala que vai de muito baixo, passando por baixo, médio, alto e muito alto. Ao observamos tais características e o processo de evolução do território do noroeste mineiro, podemos afirmar que são decorrentes do processo histórico de ocupação e gestão territorial.

É nesse contexto regional que se insere o município de Natalândia. Atualmente, o município de Natalândia possui uma área de 468,660 km², e uma população de 3280 pessoas estando 2471 situadas na zona urbana e 809 na zona rural (IBGE, 2010). Quando comparamos com o Censo Demográfico do ano 2000, também elaborado pelo IBGE, percebemos que a população urbana sofreu um ligeiro acréscimo de $4,7 \%$, passando de 2355 habitantes no ano 2000, para 2471 no ano de 2010. Já quando relatamos a situação da população do campo, percebemos uma queda de 13,8\%, passando de 933 habitantes em 2000, para 809 habitantes em 2010. A partir de uma análise dos dados em conjunto com a pirâmide etária do município, podemos entender que parte da população, em sua maioria jovens, acaba por sair da do município, sobretudo do campo, em busca do que consideram como novas oportunidades.

A economia do município é baseada predominantemente na agricultura de subsistência e na pecuária leiteira e de corte. A renda média da população é de $\mathrm{R} \$ 408,75$ per capita, sendo que $73,47 \%$ da população estão vulneráveis à pobreza (IBGE, 2010). No que se refere aos índices de saneamento básico, o município não conta com serviços de tratamento de água e apenas $54,1 \%$ do esgoto é coletado e tratado. Além disso, apenas 0,5\% dos domicílios urbanos contam com uma infraestrutura de urbanização adequada (calçadas, pavimentação, meio fio e bueiros) (IBGE, 2010).

É nesse contexto que as comunidades e os movimentos camponeses do município de Natalândia perceberam a necessidade de oferecer uma educação que estivesse contextualizada com a realidade e as demandas das populações da região, prioritariamente, os sujeitos oriundos de assentamentos da reforma agrária e da agricultura camponesa. Assim, os assentados dos Projetos de Assentamento Saco do Rio Preto, Mangal e Mamoneiras, no município de Natalândia, se envolveram no projeto de constituição de uma escola da/para a comunidade. Posteriormente, percebendo a importância e a extensão dessa luta, os municípios vizinhos de Dom Bosco, Bonfinópolis de Minas, Riachinho e Brasilândia de Minas integraram-se, dando força ao movimento. 


\section{REVISTA ELETRÔNICA \\ DA GRADUAÇÃO/PÓS-GRADUAÇÃO EM EDUCAÇÃO \\ UFG/REJ}

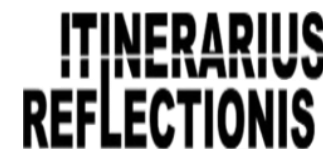

ISSN. 1807-9342

Volume 14, N. 2, 2018

Com a perspectiva da criação da escola, em 15 de abril de 2003, foi criada a Associação Escola Família Agrícola de Natalândia (AEFAN), com sede no Projeto de Assentamento Saco do Rio Preto, criada em parceria com os demais assentamentos. A AEFAN é uma entidade civil, sem fins lucrativos, composta de famílias, pais e mães, educandos e entidades afins, que tem como área de abrangência todo o noroeste do estado de Minas Gerais. A criação da associação teve como objetivo a luta por direitos que atendessem as necessidades das comunidades que a compunham, entre eles, a necessidade de maior urgência naquele momento, a criação de uma escola na comunidade.

[...] a Neli, foi a primeira presidente, ela já tinha formado, formado na área do campo né, formação técnica que ela tinha. Aí ela tinha aquela proposta de uma escola com formação técnica, uma escola diferenciada dessa tradicional. Ai a gente ficou né, conversando. A gente não conhecia nenhuma escola desse nível diferente, mas a gente foi conversando e nós mesmo que decidiu, o assentamento, o INCRA só veio para demarcar, tirar essa área da escola, que já tinha convencido o pessoal dessa importância de criar a escola [...] a gente não sabia como, que escola. Sabia que queria uma escola diferenciada, mas que modelo de escola? A gente não conhecia nenhuma ainda. A gente foi buscando os conhecimentos, de modelos de escola, qual que adaptava com a nossa realidade, a gente trouxe o modelo dessa escola aqui da Escola Bom Tempo, de Medina. Ai a gente conheceu a liderança, eu era a liderança da federação da época, estadual de mulheres, então reunia mulher do estado todo, a gente conversava muito, trocava experiências, elas traziam de lá pra cá e levavam da nossa região pra lá, as boas né, porque as ruins a gente joga fora! Eu conheci esse modelo da escola com uma colega que chama Eva e aí trouxe, vamos ver se é esse modelo que nós queremos. E chegamos num consenso de que era esse modelo de fora que nós queríamos (Liderança comunitária, entrevista realizada em agosto de 2017).

Assim, posteriormente a criação e consolidação da associação, a luta comunitária se materializou na criação e construção da qual, posteriormente, veio a ser denominada de Escola Família Agrícola de Natalândia - EFAN, já no ano de 2003 (PROJETO POLÍTICO PEDAGÓGICO - EFAN, 2015).

Atualmente, a EFAN conta com turmas dos anos finais do Ensino Fundamental ( $8^{\circ}$ e $9^{\circ}$ ano), Ensino Médio integrado ao curso de Técnico em Agropecuária $\left(1^{\circ}, 2^{\circ}\right.$ e $3^{\circ}$ ano) e, mais recentemente, em parceria com a $\mathrm{AMEFA}^{7}$, a consolidação de turmas da

\footnotetext{
${ }^{7}$ Associação Mineira das Escolas Famílias Agrícola é a entidade responsável por apoiar na organização coletiva das EFAs, bem como prestar suporte jurídico e pedagógico para as escolas de Minas Gerais.
} 


\section{REVISTA ELETRÔNICA \\ DA GRADUAÇÃO/PÓS-GRADUAÇÃO EM EDUCAÇÃO \\ UFG/REJ}

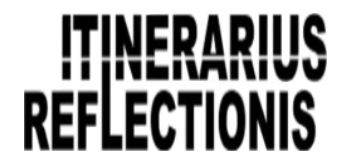

ISSN. 1807-9342

Volume 14, N. 2, 2018

Educação de Jovens e Adultos (anos iniciais e finais do Ensino Fundamental), todas em regime de alternância. Atualmente, a escola conta com 400 alunos no total, sendo 200 do Ensino Médio. Essa quantidade de alunos faz da EFAN a maior EFA no estado de Minas Gerais quando consideramos os números totais de alunos (ASSOCIAÇÃO MINEIRA DAS ESCOLAS FAMÍLIA AGRÍCOLA - AMEFA, 2016).

Especificamente no Ensino Médio integrado ao Técnico Agrícola, o currículo prevê o seu desenvolvimento com duração de três anos, em regime de alternância. São 09 alternâncias anuais, onde cada uma compreende um mês de estudos, sendo 15 dias letivos na escola (Tempo Escola - TE), complementados por mais outros 15 no meio sócio profissional (Tempo Comunidade - TC). Enquanto as turmas do $8^{\circ}$ e $9^{\circ}$ do Ensino Fundamental e $1^{\circ}$ ano do Ensino Médio estão no Tempo Escola, as turmas do $2^{\circ}$ e $3^{\circ}$ ano do Ensino Médio estão no Tempo Comunidade, e vice-versa. Dessa forma, a estrutura atualmente existente na escola é suficiente para o desenvolvimento das atividades.

A partir, fundamentalmente, da realidade da EFAN e do local em que esta se encontra inserida, posso afirmar que a escola se configura como um território, um território educativo, que não está demarcado, necessariamente, por fronteiras rígidas (o terreno da escola sim está demarcado e delimitado), pois suas ações podem se espraiar por diversos lugares e influenciar os seus sujeitos no que se refere ao modo de vida e na maneira de ver e se relacionar com o mundo.

\section{O ENSINO DE GEOGRAFIA NA EFAN}

Ficou evidente durante a pesquisa a importância do Ensino de Geografia e de seus conteúdos na formação dos alunos, através da reflexão e discussão de temas presentes no cotidiano dos mesmos. Ficou claro também, a importância da metodologia adotada pelo professor de Geografia (trabalhos coletivos, seminários, atividades práticas e resolução de problemas reais), principalmente no que se refere a autonomia e desenvolvimento da escrita, da reflexão e argumentação dos estudantes. Em relação ao Ensino de Geografia desenvolvido na EFAN, se faz importante o destaque de alguns pontos.

Primeiramente, durante a realização das entrevistas com a equipe pedagógica e alunos, sempre que falamos sobre o Ensino de Geografia, os conteúdos que mais ganham destaque são os vinculados a Geografia Física, tais como solos, relevo, vegetação, clima, cultivo agrícola, entre outros. Isso acontece primeiro, pela formação oferecida, Técnico 


\section{REVISTA ELETRÔNICA \\ DA GRADUAÇÃO/PÓS-GRADUAÇÃO EM EDUCAÇÃO \\ UFG/REJ}

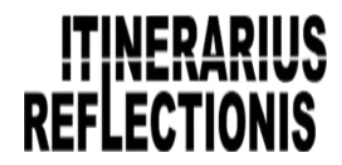

ISSN. 1807-9342

Volume 14, N. 2, 2018

Agrícola integrado ao Ensino Médio, onde os alunos possuem diversas disciplinas práticas que vivenciam, de uma maneira mais incisiva, esses conteúdos e, segundo, pela vinculação desses conteúdos com a sua realidade de vida, com seu histórico de formação, sua realidade na comunidade.

Os demais conteúdos tais como urbanização, industrialização, geografia agrária, globalização, entre outros, também apareceram, mas de maneira menos evidente e, muitas vezes, "dissolvidos” nos conteúdos vinculados a Geografia Física. A ligação entre os conteúdos de Geografia Física e Geografia Humana acaba sendo de difícil compreensão pelos alunos, principalmente pelo ensino fragmentado adotado pela disciplina que, de maneira geral, acaba por enfocar os aspectos mais familiares a realidade dos alunos e professores, em detrimento de conteúdos considerados mais complexos.

Especificamente, a formação do professor da EFAN, bem como a sua prática profissional como Técnico Agrícola nos municípios da região acabam por caracterizar e influenciar as suas ações durante o desenvolvimento da disciplina. As atividades acabam por serem mais voltadas para a prática dos conteúdos. Essa questão ficou evidente durante a roda de conversa (grupo focal) com os alunos.

Por exemplo, os conceitos e categorias fundamentais para o Ensino de Geografia e que, são vistos como fundamentais para o fortalecimento da identidade dos jovens do campo e da Educação do Campo não são discutidos diretamente em nenhum dos três anos de formação dos estudantes e são construídos, em sua maioria, a partir das ações práticas da disciplina e das atividades extraclasse desenvolvidas na EFAN.

Outro exemplo é o conceito de lugar, que traz a tona questões como a identidade dos jovens camponeses, conceito este de fundamental importância. Pela vivência e prática dos alunos em suas comunidades, associações e na luta pela terra, alguns conseguem assimilar essas diferenças, porém, não se têm um entendimento mais abrangente de todos os alunos.

Assim, a partir das reflexões realizadas até o momento, pode-se afirmar que o Ensino de Geografia desenvolvido na EFAN acaba por auxiliar no fortalecimento da Educação do Campo e, consequentemente, do jovem camponês de maneira indireta, a partir de conteúdos e atividades que trazem consigo esses conceitos e reflexões. Esse fato não deixa de ter uma relevância fundamental, principalmente pela compreensão da realidade diretamente ligada as vivências e experiências de cada um. 


\section{REVISTA ELETRÔNICA \\ DA GRADUAÇÃO/PÓS-GRADUAÇÃO EM EDUCAÇÃO \\ UFG/REJ}

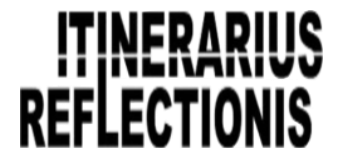

ISSN. 1807-9342

Volume 14, N. 2, 2018

A partir dessas reflexões iniciais, algumas questões ainda surgem: Será que, de fato, a Educação do Campo desenvolvida pela/ na EFAN tem alcançado os objetivos propostos? Essa Educação do Campo tem auxiliado na formação do homem do campo, na valorização dos conhecimentos e saberes? E o jovem, tem sua identidade fortalecida e busca a permanência no campo?

\section{CONSIDERAÇÕES FINAIS}

A relação entre Educação do Campo e Ensino da Geografia mostra-se profícua. Nesse sentido, quando o ensino da Geografia é orientado à realidade do educando, percebe-se a possibilidade de recuperação e potencialização do vínculo entre a formação humana e produção material da existência dessa população. Tal fato, por si só, tende a fortalecer a Educação do Campo, que deverá considerar toda bagagem trazida pelo aluno, através de seus conhecimentos e vivências compartilhados como sujeitos do campo, em um determinado território.

É necessário ressaltar, novamente, o enfoque em uma Geografia que considere todas as situações anteriormente negadas, inferiorizadas e silenciadas pelo modo de produção capitalista, construindo um novo pensamento, uma nova práxis. A ciência geográfica, nem tampouco a perspectiva escolar desse conhecimento, não poderá omitir ou negligenciar os povos do campo. Ao contrário, deverão, em conjunto com eles, auxiliar na materialização de uma Educação do Campo comprometida com o espaço de lutas campesino. Assim, a Geografia estará “[...] comprometida com o homem e a sociedade; não com o homem abstrato, mas com o homem concreto, com a sociedade tal qual ela se apresenta, dividida em classes com conflitos e contradições. E contribua para a sua transformação" (OLIVEIRA, 1994, p.143).

Na EFAN, o Ensino de Geografia auxilia no fortalecimento da identidade o do território camponês local, porém de uma maneira indireta. Os conteúdos e temas da Geografia aparecem no conjunto de ações que são desenvolvidas pela escola, enquanto a disciplina acaba por ser desenvolvida de maneira fragmentada, sem a reflexão de temas e conceitos importantes, dando ênfase a conteúdos e atividades práticas presentes no cotidiano dos alunos e do professor.

Esse fato, de maneira alguma, diminui a importância da Geografia, porém, esta poderia ter um papel mais evidente, no que diz respeito ao fortalecimento da identidade 


\section{REVISTA ELETRÔNICA \\ DA GRADUAÇÃO/PÓS-GRADUAÇÃO EM EDUCAÇÃO UFG/REJ}

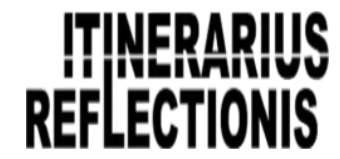

ISSN. 1807-9342

Volume 14, N. 2, 2018

do jovem e do território camponês, caso fosse desenvolvida de maneira a aproximar e refletir acerca dos conteúdos e conceitos fundamentais que se fazem presentes em todo o contexto do campo, contribuindo assim mais fortemente com a Educação do Campo no município de Natalândia - MG.

\section{REFERÊNCIAS}

ALVES, W. G; MAGALHÃES, S. M. F. O ensino de Geografia nas escolas do campo: Reflexões e propostas. Sobral: Revista da Casa da Geografia. v 10, n 1, 2008. p. 79 91.

BRASIL. Ministério da Educação. Conselho Nacional de Educação. Parecer CNE/CEB No 36/2001. Diretrizes Operacionais para a Educação Básica nas Escolas do Campo. Brasília: MEC/CNE, 2002.

CALLAI, H. C. Aprendendo a ler o mundo: a Geografia nos anos iniciais do Ensino Fundamental. Campinas: Caderno Cedes. v 25, n 66, mai/ago 2005. p. 227 - 247.

CALDART, R. S. Por Uma Educação do Campo: traços de uma identidade em construção. In: ARROYO, M. G; CALDART, R. S; MOLINA, M. C. (Orgs.). Por uma Educação do Campo. Petrópolis: Vozes, 2004. p. 147 - 158.

CALDART, R. S. Sobre a especificidade da Educação do Campo e os desafios do momento atual. Porto Alegre: Mimeo, 2015. 22 p.

CALDART, R. S. Sobre Educação do Campo. In: SANTOS, C. A. dos (Org.). Por Uma Educação do Campo: Campo - Políticas Públicas - Educação. $1^{\text {a }}$ ed. Brasília: INCRA/MDA, v. 7, 2008. p. $67-86$.

EFAN - Escola Família Agrícola de Natalândia. Projeto Político Pedagógico. Natalândia. 2015

FARIAS, A. N. et all. Transformação da forma escolar e a formação de lutadores e construtores de uma nova sociedade. In: SAPELLI, M.; FREITAS, L. C.; CALDART, R. S. Caminhos para a transformação da escola III. Rio de Janeiro: Expressão Popular, 2015. p. $143-164$.

FERNANDES, B. M. Território Camponês. In: CALDART, R. S. et al (Orgs.). Dicionário da Educação do Campo. Rio de Janeiro: Escola Politécnica de Saúde Joaquim Venâncio. São Paulo: Expressão Popular, 2012. p. 746 - 750.

FONEC - Fórum Nacional de Educação do Campo. Notas para análise do momento atual da Educação do Campo. Brasília, 2012.

FRIGOTTO, G. Educação omnilateral. In: CALDART, R. S. et al (Orgs.). Dicionário da Educação do Campo. Rio de Janeiro: Escola Politécnica de Saúde Joaquim Venâncio. São Paulo: Expressão Popular, 2012. p 


\section{REVISTA ELETRÔNICA \\ DA GRADUAÇÃO/PÓS-GRADUAÇÃO EM EDUCAÇÃO \\ UFG/REJ}

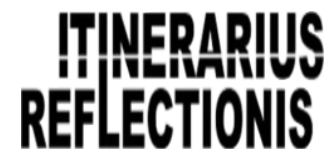

ISSN. 1807-9342

Volume 14, N. 2, 2018

HAESBAERT, R. C. O mito da desterritorialização: do "fím dos territórios" à multiterritorialidade. Rio de Janeiro: Bertrand Brasil, 2016. 400p.

IBGE - Instituto Brasileiro de Geografia e Estatística. Censos Demográficos. 2010.

LEITE, C. M. C. O Lugar e a Construção da Identidade: os significados construídos por professores de Geografia do Ensino Fundamental. 239p. Tese (Doutorado em Educação) - Programa de Pós-Graduação em Educação, Universidade de Brasília, Brasília, 2012.

LEITE, S. P.; MEDEIROS, L. S. Agronegócio. In: CALDART, R. et al (orgs.). Dicionário da Educação do Campo. Rio de Janeiro: Expressão Popular, 2012. p. 81 87.

LELIS, J. L. Territórios da informalidade: As diferentes estratégias reprodutivas das famílias inseridas no comércio informal de Viçosa-MG. 214p. Dissertação (Mestrado em Economia Doméstica) - Programa de Pós-Graduação em Economia Doméstica, Universidade Federal de Viçosa, Viçosa, 2011.

MOLINA, M. C.; MOURÃO, L. S. Escola do Campo. In: CALDART, R. et al (orgs.). Dicionário da Educação do Campo. Rio de Janeiro: Expressão Popular, 2012. p. 324 331.

MOLINA, M. C; SÁ, L. M. Escolas do Campo. In: CALDART, R. S. et al (Orgs.). Dicionário da Educação do Campo. Rio de Janeiro: Escola Politécnica de Saúde Joaquim Venâncio. São Paulo: Expressão Popular, 2012. p. 326 - 333.

OLIVEIRA, A.U. de. Educação e ensino de geografia na realidade brasileira. In: OLIVEIRA, A.U. de (Org.). Para onde vai o ensino da geografia? .4 ed. São Paulo: Pinski, 1994. p. 135-144.

OLIVEIRA, A. U.; FARIAS, C. S. Atlas da Terra e da Reforma Agrária no Brasil. In: II Convención Internacional Geografia, Medio Ambiente y Ordenamento Territorial, 2011, HAVANA. Geografia, Medio Ambiente Y Ordenamiento Territorial. Havana: Editorial Científico-Técnica, 2011. v. 1. p. 1295-1309.

OLIVEIRA, A. U. A Mundialização da Agricultura Brasileira. In: XII Colóquio Internacional de Geocrítica, 2012, Bogotá. Actas do XII Colóquio. Barcelona: Geocrítica, 2012. v. 1. p. 1-15.

RIBEIRO, M. Pedagogia da alternância na educação rural/do campo: projetos em disputa. Educação e Pesquisa. São Paulo, v 34, n 1, p. 27-45, jan/abr, 2008.

SANTOS, M. A natureza do espaço. São Paulo: EDUSP. 2009.

SANTOS, M.; SILVEIRA, M. L. O Brasil: território e sociedade no início do século XXI. $6^{\text {a }}$ ed. Rio de Janeiro: Record, 2004. 470p. 
REVISTA ELETRÔNICA

DA GRADUAÇÃ̃o/PÓS-GRADUAÇÃ̃O EM EDUCAÇÃo

UFG/REJ

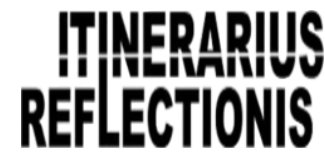

ISSN. 1807-9342

Volume 14, N. 2, 2018

SAQUET, M. A. Abordagens e concepções de território. São Paulo: Expressão popular, 2007. 200 p.

SILVA, L. H. da. Educação do Campo e Pedagogia da Alternância. A experiência brasileira. Sisífo. Ciências da Educação, 2008. p. 105 - 112.

VESENTINI, J. W. Por uma geografia crítica na escola. São Paulo: Ática, 1992. 